\title{
Features of determining capacity on double-way lines when passing high-speed passenger trains
}

\author{
Zhasurbek Abdullaev ${ }^{*}$, Marufdjan Rasulov, and Masud Masharipov \\ ${ }^{1}$ Tashkent state transport university, Tashkent, Uzbekistan
}

\begin{abstract}
Development of proposals for adapting the existing methodology for calculating the available throughput to the operating conditions of the railways of Uzbekistan, taking into account the factors that ensure traffic safety when passing high-speed passenger trains. Methods: Grapho-analytical approaches and a comparative analysis method were used to determine the throughput of railway lines with mixed train traffic. Results: The main factors influencing the capacity of lines, advantages and disadvantages for each existing method for determining the capacity of railway lines are given. To assess the quality of transportation processes on railway lines, experimental train schedules were constructed. Based on the analysis of their indicators, a formula was proposed for calculating the throughput on double-track lines when passing high-speed passenger trains. Practical significance: The application of the proposed methodology improves the calculations of the performance indicators of sections with an unparalleled train schedule.
\end{abstract}

\section{Introduction}

The technical capability of railways to ensure the transportation of passengers and goods is determined by the throughput of the main devices and structures [1]. This characteristic makes it possible to determine the possibility of developing the existing and future traffic volumes under various scenarios of the development of the economy of Uzbekistan. With insufficient development of transport infrastructure on the railway line, mixed train traffic is organized, which is the passage of high-speed, high-speed passenger and freight trains on one track. This organization is the most widespread in the world but also the most complex. Therefore, special attention is paid to the technological issues of operating railway sections with mixed traffic.

\subsection{Review and analysis of methods for determining line capacity}

Carrying capacity significantly depends on the norm of mass and length of trains, running speed, inter-train interval, type of traffic schedule, and others. Considering these factors has

\footnotetext{
*Corresponding author: zafarchik0901@ mail.ru
} 
a significant impact on the technology of organizing mixed train traffic and improving the quality of transportation [1].

There are the following types of methods for calculating the throughput and carrying capacity of the line: analytical, graphic-analytical, and a method for determining using simulation [2-5].

\subsubsection{The analytical method}

Possesses the property of universality of carrying out calculations of throughput under various conditions. However, the formal approach to determining the removal rate is rather laborious. Still, even with its help, it is impossible to consider the entire complexity of the interaction of trains of various categories with freight trains of different mass and length.

\subsubsection{Graphic-analytical method}

This method consists of building a train schedule for a given direction. However, the lack of simulation modelling of the operation of technical stations combined with adjoining sections that pass the flow of trains taking into account their mutual delays, does not allow an analysis of the resulting throughput depending on various organizational measures. Nevertheless, the standard traffic schedules allow more accurately than according to the instructions to calculate the number of trains of all categories that are planned to be passed along the railway line per day. This method does not make it possible to determine the realistically achievable throughput for the following reasons: following the current methodology, high-speed passenger trains are first laid, then the lines of ordinary passenger, suburban and group trains. Further, remaining after selecting the technological window, the graph space is uniformly filled with the travel lines of the calculated freight train, the running times of which are determined by the speed limits. In this case, it is required to lay on the graph a given number of lines for the course of calculated freight trains (heavy and long-haul). Therefore, mixed laying on the graph of lines for the movement of trains of various categories has not become widespread since this requires an increase in the effective length and number of station tracks for the formation of these trains and complicates transportation. In such conditions, the train dispatcher has to determine the possibility of passing each freight train along the next line of the schedule. At the same time, a freight train, the running time of which is longer than the calculated one, under the conditions of issuing a warning about a decrease in the set speed, can delay a passenger train and therefore, if their lines are close on the schedule, the freight train is not allowed.

Thus, the time interval between passenger trains may not be used to pass a freight train, and then the actual throughput is less determined by the standard schedule.

\subsubsection{The simulation method consists}

In multiple simulations of the movement of the flow of trains of all categories, following the tracks and stations of the railway direction, the length of which is equal to the distance from the station of formation to the station of destination. It does not require determining the calculated section and dividing it if there is a station on it with adjoining more than two directions since the resulting throughput is automatically estimated by the number of trains passing along the entire direction. The disadvantages of this method include the complexity of both the development of its tools, their postponement, verification, and the use to obtain results.

According to the Instruction on calculating the available bandwidth [1], the bandwidth is calculated using analytical formulas. So, for a double-track railway line along with the 
hauls only for calculating the one-way passage of trains, such a formula has the following form [1]:

$$
N_{\text {нал }}=\frac{\left(1440-t_{\text {mex }}\right)}{I_{\text {гр }}} \cdot \alpha_{\text {н }}
$$

where $t_{\mathrm{rex}}$ is time budget for the maintenance and repair of infrastructure; $I_{\mathrm{rp}}-$ is calculated inter-train interval of the passing direction following [7]; $\alpha_{\mathrm{H}}-$ is reliability factor of infrastructure and rolling stock.

According to [1], to calculate the maximum possible number of freight trains, set mass and length that can be passed along the line per day with a non-parallel traffic schedule, the following analytical expression is recommended:

$$
\begin{aligned}
& N_{\max }^{\Gamma \mathrm{p}}=N_{\text {нал }}-N_{c \kappa}^{\mathrm{nac}} \cdot \varepsilon_{c \kappa}^{\mathrm{nac}}-N^{\mathrm{nac}} \cdot \varepsilon^{\mathrm{nac}} \\
& -N_{n p}^{\mathrm{nac}} \cdot \varepsilon_{n p}^{\mathrm{nac}}-N_{y c} \cdot \varepsilon_{y c}-N^{\mathrm{c} \sigma} \cdot \varepsilon^{\mathrm{c} \sigma}
\end{aligned}
$$

where $N_{\text {ск }}^{\text {nac }}, N^{\text {nac }}, N_{\text {пр }}^{\text {nac }}, N_{\text {ус }}, N_{\text {сб }}-$ is the number, respectively, of high-speed, regular passenger, suburban, express freight and groupage trains or train pairs; $\varepsilon_{c \kappa}^{\mathrm{nac}}, \varepsilon^{\mathrm{nac}}, \varepsilon_{n p}^{\mathrm{nac}}, \cdot \varepsilon_{y c}, \varepsilon^{\mathrm{c \sigma}}$ - are pickup rates for freight trains by high-speed, regular passenger, suburban, express freight and groupage trains.

The work [1] recommends a formula for calculating the maximum number of freight trains with a non-parallel traffic schedule:

$$
\begin{aligned}
& N_{\max }^{\mathrm{rp}}=N_{\text {нал }} \cdot k-N_{\text {выск }}^{\mathrm{nac}} \cdot \varepsilon_{\text {выск }}^{\mathrm{nac}}-N_{c \kappa}^{\mathrm{nac}} \cdot \varepsilon_{c \kappa}^{\mathrm{nac}}- \\
& -N^{\mathrm{nac}} \cdot \varepsilon^{\mathrm{nac}}-N_{n p}^{\mathrm{nac}} \cdot \varepsilon_{n p}^{\mathrm{nac}}-N_{y c} \cdot \varepsilon_{y c}-N^{\mathrm{c} \tilde{}} \cdot \varepsilon^{\mathrm{c} \tilde{}}
\end{aligned}
$$

where $k-$ is coefficient the filling factor of capacity, $k=0.99 ; N_{\text {выск }}^{\text {nac }}-$ is number of high-speed passenger trains, respectively a train or a pair of trains; $\varepsilon_{\text {выск }}^{\text {nac }}-$ is pickup rate of freight trains by high-speed passenger trains.

Following [1], to calculate the capacity on double-track railway lines, which at some time of the day pass oncoming freight and ordinary passenger trains in the opposite direction, that is, the principle of single-track railway lines is used, is determined by the following formula:

$$
N_{\text {нал }}=\frac{\left(1440-t_{\text {mex }}\right) \cdot \alpha_{\mathrm{H}}-T_{3}}{I_{\text {гр }}}
$$

where $T_{3}-$ is time of passage of oncoming freight and passenger trains in the opposite direction, $\min$.

The time of passage of oncoming freight and passenger trains in the opposite direction is determined by the formula [1]: 


$$
T_{3}^{\kappa}=n_{\text {nac }} \cdot t_{\text {nac }}+\left(k_{1}-1\right) \cdot I_{z p}+n_{c p} t_{2 p}+\left(k_{2}-1\right) \cdot I_{z p}
$$

where $n_{\text {nac }}, n_{\imath p}-$ is number of packages of passenger and freight trains, respectively, passed in the opposite direction, train;

$t_{n a c}, t_{2 p}-$ is travel time for passenger and freight trains, taking into account station intervals, respectively, min;

$k_{1}, k_{2}-$ is the number of passenger and freight trains in packages, respectively.

However, formulas (1) - (4) do not consider the influence of such elements of carrying capacity as the interval of non-simultaneous arrival and departure of trains in cases where there should be no meetings of high-speed and freight trains on double-track sections.

\section{Methods}

There are no generally accepted mathematical formulas for assessing the throughput on existing (modernized) double-track routes with mixed traffic in cases where there should be no meetings of high-speed passenger trains with freight trains. To determine the throughput on double-track lines in such conditions, it is required to develop an analytical method for calculating the throughput of double-track lines when organizing mixed traffic of trains of various categories.

\section{Results and Discussion}

\subsection{Assessment of throughput on double-track sections}

Theoretical studies and practical experience in the operation of railways indicate that when the speed of passenger trains increases, trains of other categories are removed from the schedule.

When building a train schedule, it is necessary to ensure train traffic safety on the site. It is necessary to observe special conditions on the sections of the directions: to carry out work on the current maintenance and repair of the track, railway automation and tele mechanics systems (RATS) and communications, the schedule must provide for daily "windows" lasting up to 4 hours; in front of the high-speed train, there should be two whole runs free $[9,10]$. Compliance with the above conditions and ensuring the safety of train traffic leads to a reduction in the capacity of railway lines with mixed traffic. For example, one high-speed passenger train with mixed traffic removes from the schedule from 6 to 8 freight trains [8]. From the above, it follows that with the development of high-speed traffic in Uzbekistan on the modernized existing lines, it is necessary to consider the influence of the conditions for the passage of trains on the throughput.

To obtain a formula for calculating the throughput of a section, taking into account the above factors, we use Figure 1.

Figure 1 show a fragment of the train schedule, where the crossing of freight trains with high-speed trains is organized.

In (fig.1) the following designations are adopted:

possible line of movement of a freight train with non-stop movement; the time period during which it is possible to pass the maximum number of freight trains non-stop through the first passing intermediate station "b" (time from the moment of non-stop passage of train No. 2019 to the moment of possible non-stop passage of train No. 2001), min; $m-$ is time interval between freight train № 2019 following the first passing intermediate station 
" $b$ " and the first freight train No. 2001, having a stop at the same station, min; $t_{x}^{2^{\prime}}, t_{x}^{2}-$ is transit time of a freight train along with the first haul and a railway section, taking into account the time for acceleration and deceleration, $\min ; t_{x}^{n^{\prime}}, t_{x}^{n}-$ is time of passage of a passenger train along with the first haul and railway section, min;

$I_{2 p}-$ is interval between freight trains, min;

$\tau_{\mathrm{cK}}, \tau_{\mathrm{H}}^{\text {пр }}-$ is interval of crossing by a freight train behind an oncoming passenger train and an interval of non-simultaneous arrival of a passenger train behind a freight train, respectively, $\min$.

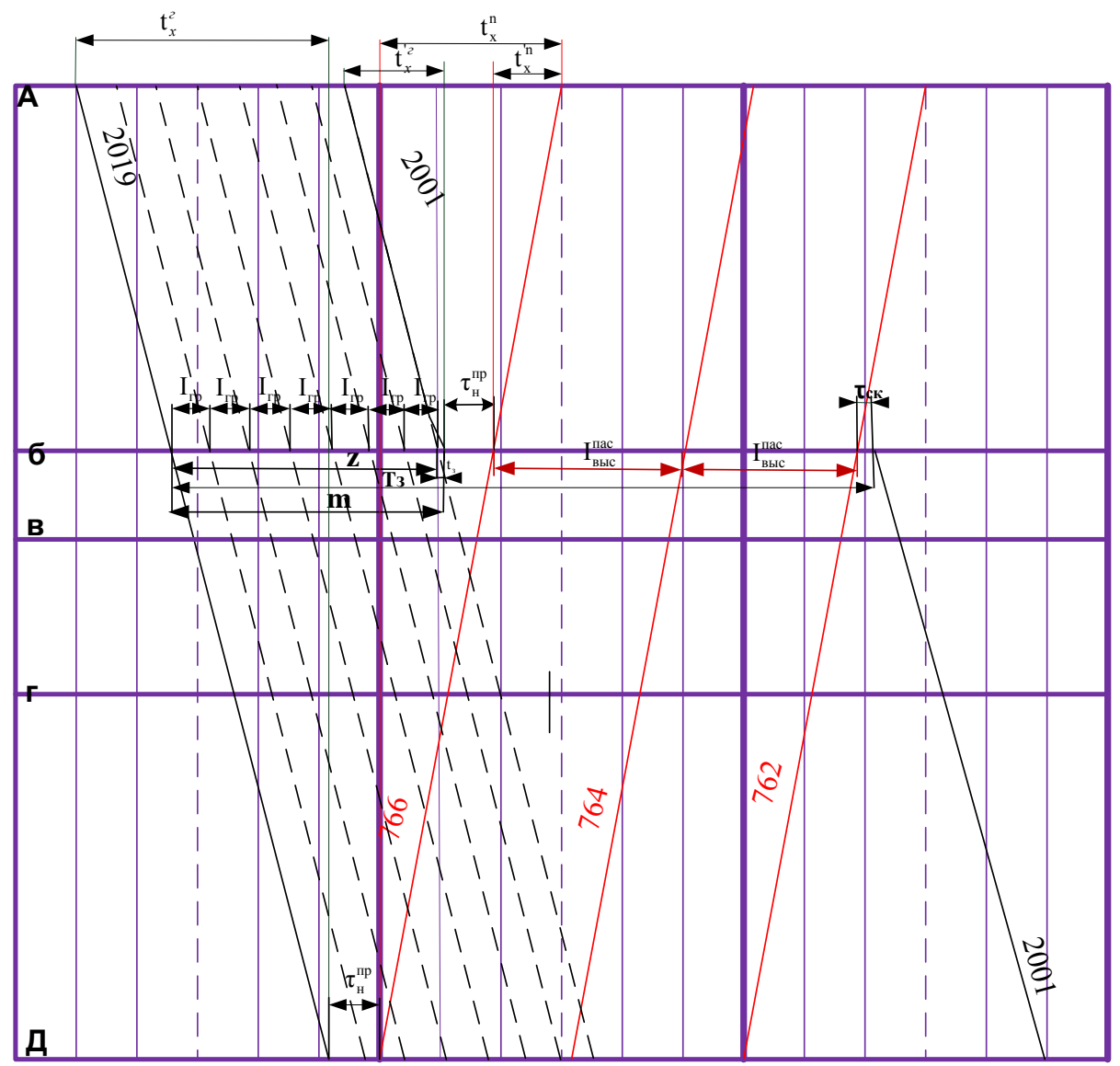

Fig. 1. Fragment of the graph of the crossing of high-speed passenger trains with freight trains

The graph shows that the value $Z$ is

$$
Z=m-1
$$

It can be seen from the graph that the value where 1 is the time for decelerating a freight train (taken based on an analysis of the standard schedule).

It follows from the figure that 


$$
m=t_{x}^{2}-t_{x}^{2}-t_{x}^{n}+t_{x}^{\prime n}
$$

Taking into account formula (9), expression (10) can be written as follows:

$$
Z=t_{x}^{2}-t_{x}^{2}-t_{x}^{n}+t_{x}^{\prime n}-1
$$

Figure 1 shows how a high-speed passenger train № 766 arriving at the site crosses with freight trains №2019, 2001. Trains № 2001 starts moving from the intermediate station "b" observing the crossing interval after the passenger train № 766 of the oncoming one passes through this station directions.

If the freight train \# 2019 proceeded non-stop through the intermediate stations of the "A-D" section to cross it by the passenger train № 766, then the value of the nonsimultaneous arrival interval $\left(\tau_{H}^{n p}\right)$ at the station " $D$ " must correspond to the minimum value $\left(\tau_{\mathrm{H}}^{\text {minпр }}\right.$ )or be more (but not more; otherwise, another line of a freight train can be laid $\tau_{H}^{n p \min }+I_{z p}-1$; between these trains):

$$
\tau_{H}^{n p \min } \leq \tau_{H}^{n p} \leq \tau_{H}^{n p \min }+I_{2 p}-1
$$

Since passenger trains are laid on the schedule in the first place, then already at this stage, it is necessary to calculate the value of the non-simultaneous arrival interval for each line and determine the average value for the entire schedule. At the same time, when finding the value of the interval of non-simultaneous arrival on a uniform segment of the time axis from $t_{H}^{n p \min }$ to $t_{H}^{n p \min }+I_{z p}-1$, with a sufficient degree of accuracy, especially with large sizes of passenger traffic, it can be calculated by the formula:

$$
t_{\mu}^{n p}=t_{H}^{n p \min }+\frac{I_{z p}-1}{2}
$$

If consider,

$$
\begin{aligned}
& t_{\sigma x}^{{ }^{2}}=t_{x}^{2}-t_{x}^{12} \\
& t_{\sigma x}^{\prime n}=t_{x}^{n}-t_{x}^{\prime n}
\end{aligned}
$$

then the time of passage of oncoming freight trains with a passenger train in the opposite direction is equal to the sum of the value of $\mathrm{Z}$, the values of the intervals of nonsimultaneous arrival, crossing, as well as the interval of passing along the route between high-speed passenger trains in a package, taking into account the additional time for acceleration and deceleration of freight trains.

(Fig. 1) it can be seen that the freight train will be sent after the passenger train in compliance with the train intervals. Then the interval of passing the oncoming freight train with the passenger at first (from the technical station) separate point is

$$
T_{3}^{1}=t_{6 x}^{\prime 2}+t_{6 x}^{\prime n}-1+I_{\text {выс }}^{n a c} \cdot\left(n_{\mathrm{Bc \kappa}}-1\right)+t_{p_{3}}+t_{3}+\tau_{H}^{n p}+\tau_{c \kappa}
$$


where $I_{\text {выс }}^{\text {nac }}$ - is inter-train interval of high-speed train, min;

$\tau_{H}^{n p}, \tau_{c \kappa}$-is time, respectively, non-simultaneous arrival and crossing of trains, min;

$t_{p_{3}}, t_{3}-$ is time for acceleration and deceleration of freight trains, min.

$t_{\delta x}^{\prime}, t_{\delta x}^{\prime n}-$ is transit time of freight and passenger trains on the section without taking into account the first haul, min;

$n_{\text {вск }}-$ is number of high-speed trains in the package, train.

In the second split paragraph

$$
T_{3}^{2}=t_{6 x}^{\prime 2}+t_{6 x}^{n}-1+I_{\text {выс }}^{n a c} \cdot\left(n_{\mathrm{вск}}-1\right)+t_{p 3}+t_{3}+\tau_{H}^{n p}+\tau_{c \kappa}
$$

At the third (before the second technical station) split point

$$
T_{3}^{3}=t_{\sigma x}^{\prime \prime 2}+t_{6 x}^{\prime \prime \prime}-1+I_{\text {выс }}^{n a c} \cdot\left(n_{\mathrm{вск}}-1\right)+t_{p_{3}}+t_{3}+\tau_{H}^{n p}+\tau_{c \kappa}
$$

At last (before the second technical station) split point

$$
T_{3}^{\kappa}=t_{\sigma x}^{k 2}+t_{c p}^{k n}-1+I_{\text {выс }}^{n a c} \cdot\left(n_{\mathrm{вс \kappa}}-1\right)+t_{p 3}+t_{3}+\tau_{H}^{n p}+\tau_{c \kappa}
$$

where $t_{\delta x}^{n n}, t_{\delta x}^{\prime 2 p}, t_{\delta x}^{\prime \prime n}, t_{\delta x}^{\prime \prime 2 p}, t_{\delta x}^{n k}, t_{\delta x}^{2 k}-$ is time of passage of freight and passenger trains along the section without taking into account the second, third and k-th runs, respectively, min; $k-$ is number of runs on the railway section under consideration.

Then the average delay time of a freight train crossing it with a high-speed passenger train for the entire section is determined by the following expression:

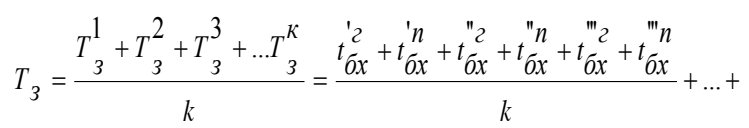

$$
\begin{aligned}
& +\frac{t_{\delta x}^{k 2}+t_{\delta x}^{k n}+\left(\tau_{H}^{n p}+\tau_{c \kappa}+t_{3}+t_{p 3}-1\right) \cdot k+I_{b b l c}^{n a c} \cdot\left(n_{\mathrm{BCK}}-1\right) \cdot k}{k}
\end{aligned}
$$

Then formula (12) should be written:

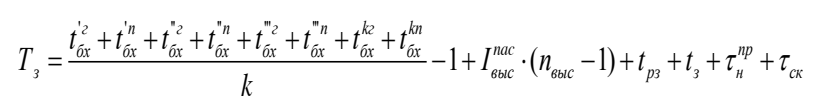

In the general case, the quantity $T_{3}$ takes the following form:

$$
T_{3}=\frac{\sum_{i=1}^{k}\left(t_{6 x}^{i 2}+t_{6 x}^{i n}\right)}{k}-1+I_{6 b c}^{n a c} \cdot\left(n_{6 b l c}-1\right)+t_{p 3}+t_{3}+\tau_{H}^{n p}+\tau_{c k}
$$

Taking into account formula (4), expression (14) can be written as follows: 


$$
N_{\text {нал }}=\frac{\left(1440-t_{\text {mex }}\right) \cdot \alpha_{\text {н }}-\left(\frac{\sum_{i=1}^{k}\left(t_{6 x}^{i 2}+t_{6 x}^{i n}\right)}{k}-1+I_{\text {bыc }}^{n a c} \cdot\left(n_{\text {sыc }}-1\right)+t_{p 3}+t_{3}+\tau_{H}^{n p}+\tau_{c k}\right)}{I_{\text {гр }}}
$$

As can be seen from the obtained formula (16), the throughput depends on the size of high-speed passenger traffic and the intervals between high-speed trains, and, consequently, the intervals of non-simultaneous arrival, a crossing of trains and inter-train intervals of freight trains, as well as on the number of runs on the section.

Figure 2 shows the results of calculating the throughput of a double-track railway section according to the existing Instructions for calculating the available throughput (ISC) and the proposed methodology, depending on the running speed of freight trains.

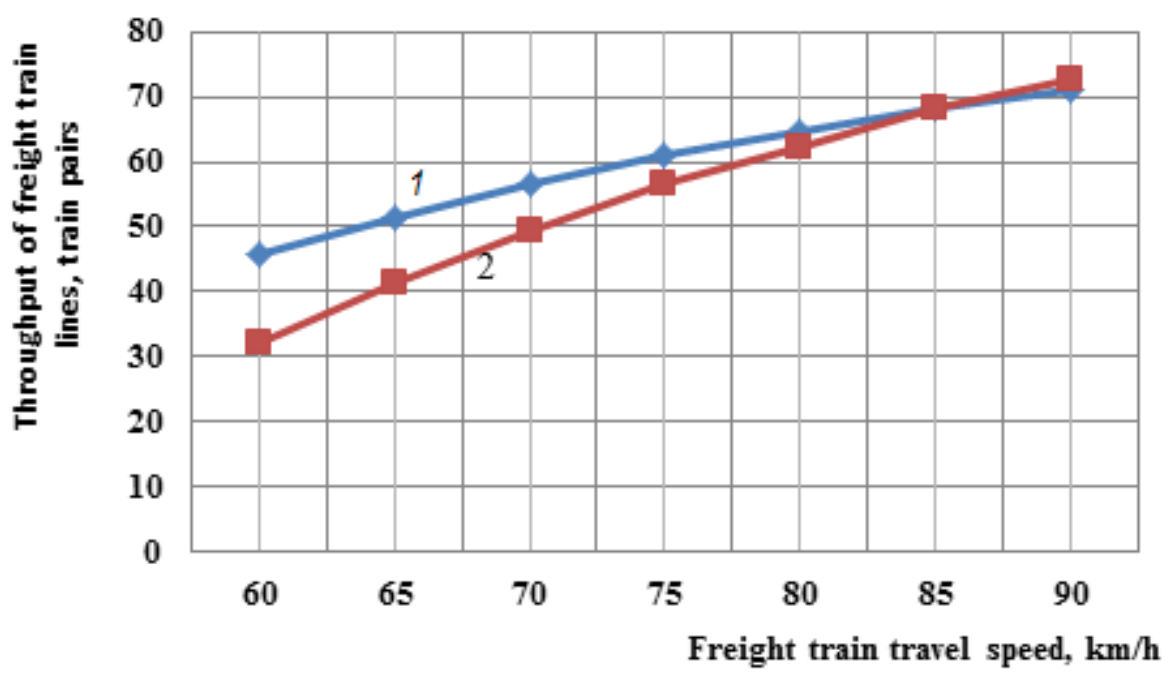

Fig. 2. Dependence of the section throughput on the speed of freight trains: 1 is according to the current methodology (ISC); 2 is according to the proposed method

As the calculation results showed, with an increase in the running speed of freight trains, the deviation of the values of the available throughput decreases according to different calculation methods. Comparative analysis showed that the results of calculating the throughput according to the current Instructions for determining the available throughput (IS) and according to the proposed method, depending on the running speed of freight trains, may have a deviation of up to $20 \%$. Comparing the results of calculations using the IRS and the method proposed by the authors allows you to analyze the state of the available throughput of sections, open up existing reserves and identify bottlenecks with a shortage of throughput.

\section{Conclusions}

The existing methods for determining the available throughput do not take into account several factors: 
- the travel time of freight trains along the railway section and the first haul taking into account the time for acceleration and deceleration;

- intervals between high-speed passenger trains in a package;

- the number of runs on the site;

- intervals of non-simultaneous arrival and crossing of trains at the station.

The use of the graphic-analytical method, provided that the above factors are adequately reflected, makes it possible to accurately determine the line capacity. However, for a preliminary assessment, you must have analytical dependencies.

In the proposed expressions (1) - (16), based on the graphic-analytical method for calculating the available throughput of railway lines, all the features of the track development of lines and the technology of the stations are taken into account, as well as the conditions for the safe passage of high-speed passenger trains.

\section{References}

1. Instructions for calculating the available throughput - approved. Order of the Ministry of Transport dated 16.07.2018, 126. - M, Ministry of Transport, p. 305, (2018).

2. Levin D. Yu. Calculation and use of the throughput of railways, D. Yu. Levin, VL Pavlov. - M, Textbook. -method. Center for Education in Railway Transport, p. 364, (2011).

3. Abramov A. A. Simulation modeling of the available capacity, A. A. Abramov, K. V. Androsyuk, Railway transport. 11. - P. 28-31. (2013).

4. Groshev GM Methods of increasing the throughput of the line with the growth of traffic, GM Groshev, Zh.Ya. Abdullaev, A.A. Grachev, A.S. Al-Shumari, A.V. Sugorovsky, Transport of the Russian Federation - SPb , PGUPS, pp. 26 - 31.( 2019).

5. Makarochkin, A.M. Use and development of the capacity of railways, A. M. Makarochkin, Yu. V. Dyakov. - M, Transport, p. 287. (1981).

6. Kokurin I. M. Methods for determining "bottlenecks" limiting the throughput of railways, I. M. Kokurin, V. S. Timchenko, Bulletin of the Petersburg University of Railways. - SPb, PGUPS, 1. pp. 15-22.( 2013)

7. Railways A.A. Instructions for determining station and inter-train intervals, approved by the vice-president of Russian Krasnoshchek 30.12. 2011, 2864 - M, JSC "Russian Railways", p. 213. (2011).

8. Borovikova M.S. Organization of high-speed traffic on the railways of the Russian Federation: study guide, Press LLC, p. 64 (2011).

9. Temporary instruction "On the procedure for maintenance and organization of the passage of high-speed electric trains, Afrosiyob, on public railways on the TashkentSamarkand section. - Tashkent: Uzgoszheldornadzor, p. 36, ( 2011)

10. Instruction On the procedure for servicing and organizing the passage of high-speed electric trains, Afrosiyob on public railways on the section Tashkent - Samarkand Karshi, Tashkent - Samarkand - Bukhara" - Tashkent: Uzgoszheldornadzor, p.34, (2016). 